\title{
Effect of Chronic Hyperglycemia on In Vivo Insulin Secretion in Partially Pancreatectomized Rats
}

Luciano Rossetti, Gerald I. Shulman, Walter Zawalich, and Ralph A. DeFronzo

Yale University School of Medicine and School of Nursing, New Haven, Connecticut 06510

\begin{abstract}
We have examined the effect of chronic (4 wk) hyperglycemia on insulin secretion in vivo in an awake, unstressed rat model. Three groups of animals were examined: control, partial (90\%) pancreatectomy, and partial pancreatectomy plus phlorizin, in order to normalize plasma glucose levels. Insulin secretion in response to arginine $(2 \mathrm{mM})$, hyperglycemia $(+100 \mathrm{mg} / \mathrm{dl})$, and arginine plus hyperglycemia was evaluated. In diabetic compared with control animals three specific alterations were observed: (a) a deficient insulin response, in both first and second phases, to hyperglycemia; (b) an augmented insulin response to the potentiating effect of arginine under basal glycemic conditions; and $(c)$ an inability of hyperglycemia to augment the potentiating effect of arginine above that observed under basal glycemic conditions. Normalization of the plasma glucose profile by phlorizin treatment in diabetic rats completely corrected all three beta cell abnormalities. These results indicate that chronic hyperglycemia can lead to a defect in in vivo insulin secretion which is reversible when normoglycemia is restored.
\end{abstract}

\section{Introduction}

Glucose is the primary regulator of insulin secretion in vivo. It exerts this role by stimulating directly the beta cell and by modulating the effect of other secretagogues $(1,2)$. In contrast to acute intermittant elevations in the plasma glucose concentration, which provide a powerful insulin secretory stimulus to the beta cell, Weir et al. have advanced the hypothesis that chronic sustained hyperglycemia, in the presence of a reduced beta cell mass, may lead to the development of a defect in insulin secretion (3). Over the years, much evidence has accumulated to indicate that the beta cells of diabetic man $(4,5)$ and animals (6-9) have acquired a specific defect in their ability to respond to glucose. In contrast, the pancreas' response to nonglucose secretagogues such as arginine (9), leucine (7), sulfonylurea drugs $(10)$, and isoproterenol $(10,11)$ is well maintained. Similarly, the ability of glucose to modulate the insulin response to these nonglucose secretagogues is consistently impaired $(7,9)$. However, the precise factors that are responsible for the beta cells" "blindness" to glucose have yet to be defined.

Address correspondence to Dr. Rossetti, 2071 LMP Bldg., Yale-New Haven Hospital, 333 Cedar St., New Haven, CT 06510.

Received for publication 23 January 1987 and in revised form 18 May 1987.

J. Clin. Invest.

(c) The American Society for Clinical Investigation, Inc. 0021-9738/87/10/1037/08 \$2.00

Volume 80, October 1987, 1037-1044
In the present study we have examined, for the first time in vivo, whether chronic hyperglycemia can lead to the development of a defect in insulin secretion in otherwise healthy beta cells, and whether restoration of normoglycemia can correct the impairment in insulin secretion. To bring about a reduction in beta cell mass and produce a state of chronic hyperglycemia, a $90 \%$ surgical pancreatectomy was performed (12). The remaining $10 \%$ of the pancreas is left intact, and insulin secretion, expressed per remaining pancreatic mass, should be normal unless some acquired defect in beta cell function develops. To examine whether any acquired beta cell abnormality was specifically the result of chronic exposure to hyperglycemia, diabetic rats received a continuous infusion of phlorizin for $4 \mathrm{wk}$. This agent induces renal glucosuria and leads to normal fasting and near normal postmeal plasma glucose levels (13). The ability of the pancreas to secrete insulin was evaluated using the hyperglycemic clamp technique (14) so that the early and late phases of insulin secretion could be examined separately and compared with the response to arginine.

\section{Methods}

Animal preparation. Three groups of male Sprague-Dawley rats (Charles River Breeding Laboratories, Wilmington, MA), weighing between 80 and $100 \mathrm{~g}$ (3-4 wk old) were studied. Group I: sham-operated controls $(n=7)$; group II: partially pancreatectomized rats ( $n$ $=10$ ); and group III: partially pancreatectomized rats treated with phlorizin $(n=6)$. All rats (3-4 wk old) were anesthesized with phenobarbital $(50 \mathrm{mg} / \mathrm{kg}$ body wt), and in groups II and III $90 \%$ of the pancreas was removed according to the technique of Foglia (12), as modified by Bonner-Weir et al. (3). Group I animals underwent a sham pancreatectomy in which the pancreas was disengaged from the mesentery and gently rubbed between the fingers. Postoperatively, rats were housed in an environmentally controlled room with a 12-h light/ dark cycle and allowed free access to standard rat chow (Ralston-Purina Co., St. Louis, MO) and water. Within $48 \mathrm{~h}$ all animals had recovered from surgery and were eating normally. In group III rats phlorizin $(0.4 \mathrm{~g} / \mathrm{kg}$ body wt per $\mathrm{d}$ made up in a $20 \%$ solution of propylene glycol $)$ treatment was initiated $14 \mathrm{~d}$ postsurgery, at a time when hyperglycemia first became evident in the partially pancreatectomized rats and was continued for $4 \mathrm{wk}$. Phlorizin was administered as a continuous subcutaneous infusion through a small implantable minipump (Alzet osmotic minipump; Alza Corp., Palo Alto, CA) to ensure day-long inhibition of renal tubular glucose reabsorption. After surgery, rats were weighed twice weekly and tail vein blood collected at the same time for the determination of fed plasma glucose and insulin concentrations.

5 wk postpancreatectomy and sham operation (i.e., 1 wk before performing the hyperglycemic clamp study) rats were anesthesized with phenobarbital $(50 \mathrm{mg} / \mathrm{kg}$ body wt) and indwelling catheters were inserted so that the animals could be studied in the awake, unstressed state. Two internal jugular catheters were inserted and extended to the level of the right atrium and a left carotid catheter was advanced to the aortic arch. The three catheters were filled with heparin/polyvinylpyr- 
rolidone solution, sealed, and tunneled subcutaneously around the side of the neck to the back of the head. The catheters were externalized through a skin incision and anchored to the skull with a dental cement cap (Durelon; Premier Co., Norristown, PA), which was reinforced by four jeweler's case screws $(0.07 \mathrm{~mm})$.

Experimental protocol. All studies were conducted in the morning after a 10-12-h overnight fast. Throughout the study, the rats were allowed to move freely within the confines of a large cage and the connecting tubing was suspended overhead by means of a pulley system. The venous catheter was used for blood withdrawal and the arterial catheter for infusion of all test substances. To prevent intravascular volume depletion and anemia, fresh whole blood obtained by heart puncture from littermates of the test animal was administered at a constant rate designed to quantitatively replace the total blood loss during the study.

Arginine/hyperglycemic clamp study (Fig: 1). Blood was obtained for the determination of plasma glucose and insulin concentration at -30 and $0 \mathrm{~min}$. At time zero a prime-continuous infusion of arginine solution $(300 \mathrm{mg} / \mathrm{ml})$ was administered from time $0-30 \mathrm{~min}$ to acutely raise and maintain the plasma arginine concentration at $\sim 2 \mathrm{mM}$. The prime was administered at the rate of $280 \mu \mathrm{mol} / \mathrm{min}$ from 0 to $2 \mathrm{~min}$ and the continuous infusion was administered at $36 \mu \mathrm{mol} / \mathrm{min}$ from 2 to $30 \mathrm{~min}$. Blood for the determination of plasma glucose and insulin concentrations was obtained at time $2,4,6,8,10,20$, and 30 min after starting the arginine infusion. Between time 30 and 80 min a constant saline infusion ( $15 \mu \mathrm{l} / \mathrm{min}$ ) was administered to maintain the arterial catheter patent. Blood samples were withdrawn at time 60 and 80 min for determination of plasma glucose and insulin levels. At time $80 \mathrm{~min}$ a priming infusion of $25 \%$ glucose was administered to acutely raise the plasma glucose concentration by $\sim 100 \mathrm{mg} / \mathrm{dl}$ above baseline. The plasma glucose concentration was subsequently held constant at this hyperglycemic plateau until time $170 \mathrm{~min}$ by the adjustment of a variable glucose infusion based upon a negative feedback principle (14). Plasma samples for determination of glucose and insulin were obtained at 2-min intervals between time 80 and $90 \mathrm{~min}$ and at $10-\mathrm{min}$ intervals thereafter until $140 \mathrm{~min}$. From 140 to $170 \mathrm{~min}$ a prime-continuous infusion of arginine was again administered as previously described. Plasma arginine concentration was determined at time $-30,0$, $10,30,80,150$, and $170 \mathrm{~min}$.

Pancreatic weight and insulin content. $4 \mathrm{~d}$ after the arginine/hyperglycemic clamp study all rats, after a 12 -h overnight fast, were anesthesized and the pancreas was quickly dissected, separated from gut and major lymph nodes, rinsed in saline, blotted, and weighed. The pancreatic tissue was then frozen in liquid nitrogen and stored at $-30^{\circ} \mathrm{C}$ for subsequent insulin analysis. The tissue was homogenized in ice-cold acid-ethanol $(0.15 \mathrm{M} \mathrm{HCl}-75 \%$ ethanol) and incubated for 48 $\mathrm{h}$ at $4^{\circ} \mathrm{C}$. After incubation the suspension was centrifuged for $10 \mathrm{~min}$ at $10,000 \mathrm{rpm}$ in a Sorval refrigerated centrifuge. The supernatant was decanted and a 1:1,000 dilution was prepared in phosphate-buffered saline solution containing $\mathbf{0 . 2 5 \%}$ bovine serum albumin. Insulin concentration was measured in quadruplicate using a rat insulin standard
(Eli Lilly \& Co., Indianapolis, IN). All insulin determinations were performed in the same assay to eliminate any interassay variations.

Analytical procedures. Plasma glucose was measured by the glucose oxidase method (glucose analyzer, Beckman Instruments Inc., Palo Alto, CA) and plasma insulin by radioimmunoassay using rat insulin (lot 615-D63-12-3; Eli Lilly \& Co.) as standard (15). Plasma arginine concentration was determined by an automated ion exchange chromatographic technique (D-500; Dionex Corp., Sunnyvale, CA) with an L6 column and lithium citrate buffer.

Calculations. The plasma insulin responses presented in Tables III-V represent the mean increment in plasma insulin concentration above baseline during the 0-30 (arginine infusion)-, 80-140 (glucose infusion)-, 140-170 (arginine plus glucose infusion)-min time intervals. The basal insulin concentration for the arginine infusion was calculated as the mean of the -30 - and 0 -min plasma insulin concentrations. The baseline plasma insulin concentration for the glucose infusion was calculated as the mean of the 70 - and 80 -min time points. The baseline plasma insulin concentration for the combined glucose/ arginine infusion period was calculated as the mean of the 130 - and 140 -min time points. All values are presented as the mean \pm SEM. Significant differences between groups were determined using the one-way analysis of variance in conjunction with the Student-Newman-Kuel test.

\section{Results}

Body weight, plasma glucose, and insulin concentrations. All animals were studied $6 \mathrm{wk}$ after pancreatectomy or sham pancreatectomy. At this time no significant differences in body weight were observed between any of the three groups (Table I). The fasting (mean of four values during the 2 wk before study) and fed plasma glucose concentrations are shown in Table I. In group II rats ( $90 \%$ pancreatectomy) the fasting plasma glucose concentration was slightly increased (both $P$ $<0.01$ ) compared with both groups I (sham-operated controls) and III (phlorizin-treated diabetic rats). The fasting plasma glucose in phlorizin-treated diabetic animals was slightly but not significantly elevated compared with controls. The fed plasma glucose concentration in diabetic rats was approximately twice that observed in controls $(P<0.001)$. Before the initiation of phlorizin treatment at $2 \mathrm{wk}$ after pancreatectomy, the fed plasma glucose $(296 \pm 19 \mathrm{mg} / \mathrm{dl})$ was similar to that observed in the diabetic group ( $284 \pm 13 \mathrm{mg} / \mathrm{dl})$. After $4 \mathrm{wk}$ of phlorizin therapy (group III), the fed plasma glucose concentration was reduced to levels similar to those in controls.

The fasting plasma insulin concentration was similar in all three groups. The fed plasma insulin concentration was similarly reduced in groups II and III compared with controls $(P$ $<0.001)$.

Table I. Fasting and Fed Plasma Glucose and Insulin Concentrations in Control and Diabetic Rats*

\begin{tabular}{|c|c|c|c|c|c|c|}
\hline Group & Number & Weight & $\begin{array}{l}\text { Fasting plasma } \\
\text { glucose }\end{array}$ & Fed plasma glucose & $\begin{array}{l}\text { Fasting plasma } \\
\text { insulin }\end{array}$ & Fed plasma insulin \\
\hline & & $g$ & $m g / d l$ & $m g / d l$ & $n g / m l$ & $n g / m l$ \\
\hline I Sham operated & 7 & $276 \pm 7$ & $103 \pm 2$ & $143 \pm 2$ & $2.44 \pm 0.16$ & $5.79 \pm 0.24$ \\
\hline II Diabetic & 10 & $264 \pm 9$ & $119 \pm 3^{\ddagger}$ & $284 \pm 13^{8}$ & $2.37 \pm 0.20$ & $3.04 \pm 0.15^{8}$ \\
\hline III Phlorizin-treated diabetic & 6 & $258 \pm 11$ & $111 \pm 3$ & $\begin{array}{c}142 \pm 6 \\
(296 \pm 19)^{\prime \prime}\end{array}$ & $2.50 \pm 0.15$ & $2.95 \pm 0.20^{5}$ \\
\hline
\end{tabular}

* All values represent the mean \pm SEM. ${ }^{\ddagger} P<0.01$ vs. sham-operated control rats. ${ }^{8} P<0.001$ vs. sham-operated and phlorizin-treated diabetic rats. "Fed plasma glucose concentration in the same six rats before the institution of phlorizin treatment (i.e., at week two). 
Pancreatic insulin content (Table II). Pancreatic weight and insulin content in groups II and III were similarly and markedly decreased to $\sim 15 \%$ of the sham-operated control group $(P<0.001)$. The decrease in pancreatic insulin content closely paralleled the reduction in pancreatic mass in all rats.

Plasma glucose and insulin concentrations during arginine/glucose infusion (Figs. 1 and 2; Table III). After an overnight fast (2200-0900 h) plasma arginine concentrations were $152 \pm 4 \mu \mathrm{M}$ in group I, $194 \pm 12 \mu \mathrm{M}$ in group II, and $187 \pm 15$ $\mu \mathrm{M}$ in group III. Arginine infusion (0-30 min) resulted in steady state plasma arginine levels that were similar in all three groups: $2,187 \pm 199 \mu \mathrm{M}$ in group I, 2,319 $\pm 99 \mu \mathrm{M}$ in group II, and 2,357 $\pm 107 \mu \mathrm{M}$ in group III. The plasma glucose concentration increased slightly (by $10-20 \mathrm{mg} / \mathrm{dl}$ ) and similarly in the three groups during arginine infusion (Fig. 1). The mean incremental plasma insulin response to arginine was reduced by $54 \%$ in the diabetic group and by $84 \%$ in the diabetic rats treated with phlorizin $(P<0.001)$ (Table III).

By the end of the 30-80-min period of saline infusion, plasma glucose and insulin concentrations returned to basal, pre-arginine infusion levels (Figs. 1 and 2). During the $1 \mathrm{~h}$ hyperglycemic clamp study $(80-140 \mathrm{~min})$ the increment in plasma glucose concentration was $96 \pm 2,99 \pm 4$, and $99 \pm 4$ $\mathrm{mg} / \mathrm{dl}$ in groups I, II, and III, respectively. In all studies the coefficient of variation in plasma glucose concentration was $<5 \%$. The glucose infusion rate (140-180-min period) necessary to maintain the plasma glucose concentration constant at the desired hyperglycemic plateau was $24.3 \pm 1.2,4.3 \pm 0.3$, and $7.3 \pm 0.4 \mathrm{mg} / \mathrm{kg} \cdot \mathrm{min}$ in groups I, II, and III, respectively. The mean plasma insulin response in the diabetic group was reduced by $95 \%$ compared with controls $(0.30$ vs. $5.75 \mathrm{ng} / \mathrm{ml}, P$ $<0.001$ ). In phlorizin-treated diabetic rats the mean plasma insulin response $(0.91 \mathrm{ng} / \mathrm{ml})$ was increased threefold $(P$ $<0.01)$ compared with the diabetic group, but was still much reduced compared with controls when viewed in absolute terms (Table III).

When an arginine infusion (140-170 $\mathrm{min}$ ) was superimposed on hyperglycemia, the mean incremental plasma insulin response $(20.61 \mathrm{ng} / \mathrm{ml})$ was significantly greater than the additive effects of hyperglycemia $(5.75 \mathrm{ng} / \mathrm{ml})$ alone or arginine $(3.80 \mathrm{ng} / \mathrm{ml})$ alone. During combined arginine/glucose infusion, the mean plasma incremental response in both group II and group III rats was reduced by $\sim 90 \%$ compared with controls $(P<0.001)$.

Since diabetic animals had $90 \%$ of their pancreas removed, it is not surprising that the plasma insulin response, when viewed in absolute terms, was deficient. Therefore, the incremental plasma insulin responses were also calculated per gram of pancreatic tissue and per pancreatic insulin content (Table IV). Since pancreatic weight and insulin content were highly

Table II. Pancreatic Weight and Insulin Content in Control and Diabetic Rats

\begin{tabular}{lccc}
\hline Group & Number & Pancreatic weight & Insulin content \\
\hline & & $g$ & $\mu g /$ pancreas \\
I Sham operated & 7 & $1.32 \pm 0.031$ & $51.7 \pm 12.4$ \\
II Diabetic & 10 & $0.194 \pm 0.012$ & $8.5 \pm 3.2$ \\
III Phlorizin-treated diabetic & 6 & $0.188 \pm 0.020$ & $7.1 \pm 2.8$ \\
\hline
\end{tabular}

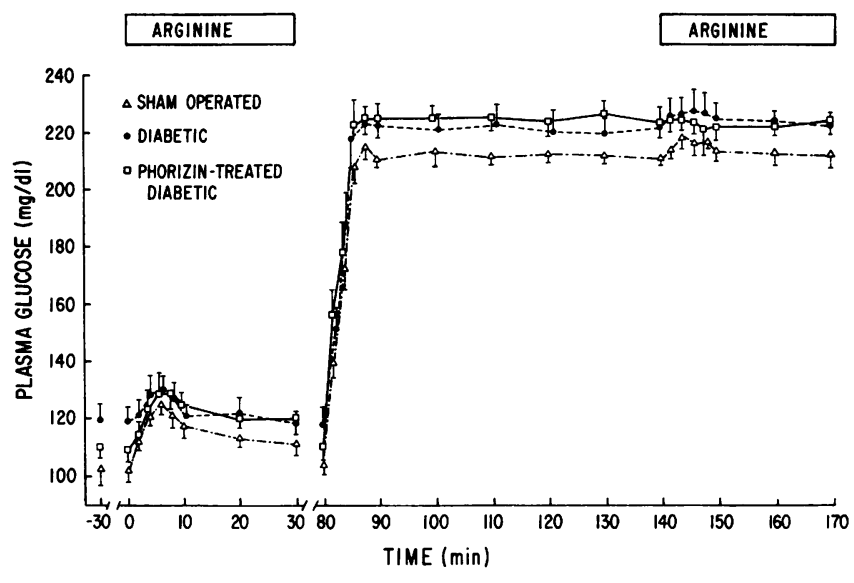

Figure 1. Plasma glucose concentration (milligrams per milliliter) during arginine infusion ( $t=0-30 \mathrm{~min}$ ), during the hyperglycemic clamp $(t=80-140 \mathrm{~min})$, and during combined arginine plus glucose infusion ( $t=140-170 \mathrm{~min}$ ) in group I (sham operated, open triangles), in group II (diabetic, solid circles), and in group III (phlorizintreated diabetic, open squares).

correlated $(r=0.95, P<0.001)$, both methods of data expression yielded qualitatively and quantitatively similar results. The incremental plasma insulin response to arginine in dia-
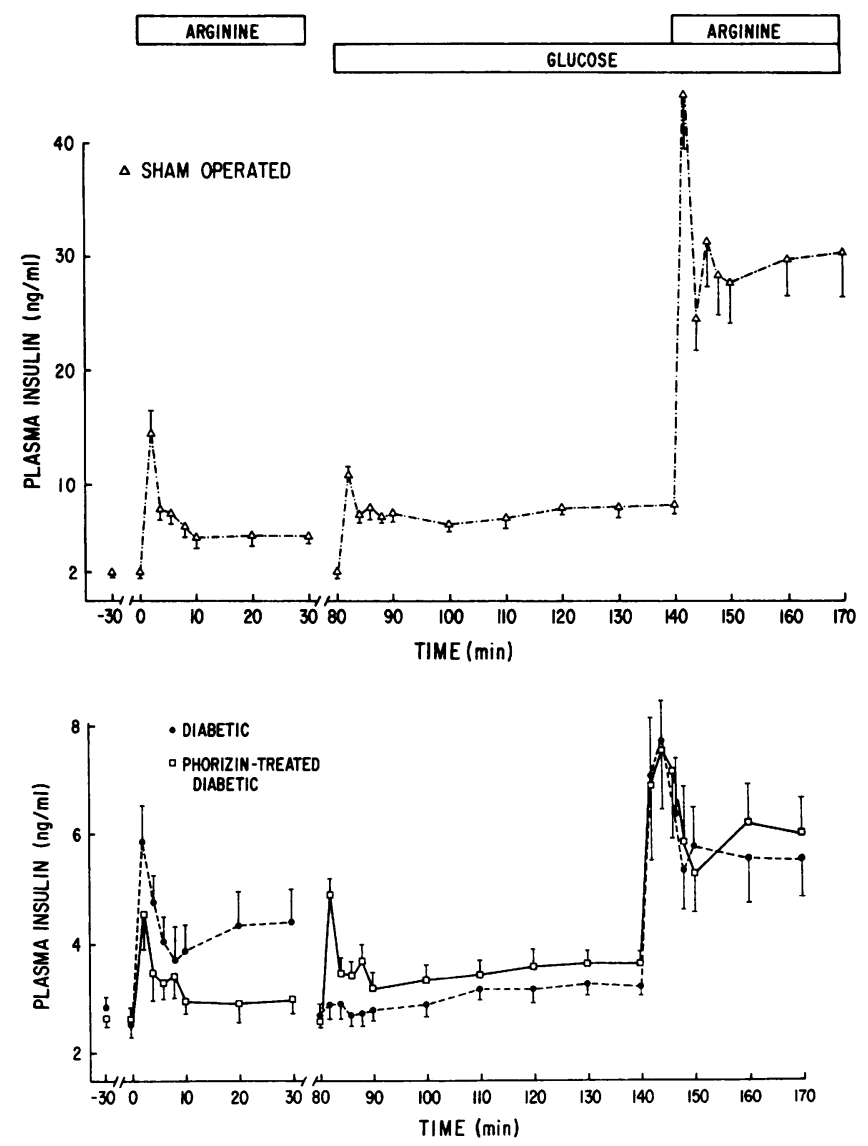

Figure 2. Plasma insulin concentration (nanograms per milliliter) during arginine infusion ( $t=0-30 \mathrm{~min}$ ), during the hyperglycemic clamp $(t=80-140 \mathrm{~min})$, and during combined arginine plus glucose infusion ( $t=140-170 \mathrm{~min}$ ) in group I (sham operated, open triangles, top), group II (diabetic, solid circles, bottom), group III (phlorizin-treated diabetic, open squares, bottom). 
Table III. Plasma Glucose Concentrations and Mean Incremental Plasma Insulin Responses after Arginine, Glucose, and Combined Arginine/Glucose Infusion in Control and Diabetic Rats

\begin{tabular}{|c|c|c|c|c|c|c|}
\hline \multirow[b]{2}{*}{ Group } & \multicolumn{3}{|c|}{ Mean plasma glucose concentration $(\mathrm{mg} / \mathrm{dl})$} & \multicolumn{3}{|c|}{ Mean increment plasma insulin concentration $(\mathrm{ng} / \mathrm{ml})$} \\
\hline & $\begin{array}{l}\text { Arginine } \\
(0-30 \mathrm{~min})\end{array}$ & $\begin{array}{l}\text { Hyperglycemia } \\
\text { (80-140 min) }\end{array}$ & $\begin{array}{l}\text { Arginine } \\
+ \text { hyperglycemia } \\
\text { (140-170 min) }\end{array}$ & $\begin{array}{l}\text { Arginine } \\
(0-30 \mathrm{~min})\end{array}$ & $\begin{array}{l}\text { Hyperglycemia } \\
(80-140 \mathrm{~min})\end{array}$ & $\begin{array}{l}\text { Arginine } \\
+ \text { hyperglycemia } \\
(140-170 \mathrm{~min})\end{array}$ \\
\hline I Sham operated & $115 \pm 3$ & $211 \pm 2$ & $213 \pm 4$ & $3.80 \pm 0.41$ & $5.75 \pm 0.75$ & $20.61 \pm 3.26$ \\
\hline II Diabetic & $122 \pm 5$ & $221 \pm 4$ & $225 \pm 5$ & $1.73 \pm 0.35^{*}$ & $0.30 \pm 0.05^{*}$ & $2.46 \pm 0.62^{*}$ \\
\hline III Phlorizin-treated diabetic & $126 \pm 3$ & $225 \pm 5$ & $223 \pm 5$ & $0.52 \pm 0.15^{\ddagger}$ & $0.91 \pm 0.09 * \pm$ & $2.21 \pm 0.53^{*}$ \\
\hline
\end{tabular}

${ }^{*} P<0.001$ vs. group I. ${ }^{\ddagger} P<0.01$ vs. group II.

betic rats was increased threefold compared with controls ( $P$ $<0.001)$, and phlorizin treatment normalized this hyperinsulinemic response (Table IV). In contrast to arginine, the incremental insulin response to hyperglycemia was reduced by $\sim 65 \%$ in the diabetic group ( $1.5 \mathrm{vs.} 4.4 \mathrm{ng} / \mathrm{ml}$ per g pancreas), and this defect in insulin secretion was totally corrected by phlorizin treatment $(4.8 \mathrm{ng} / \mathrm{ml}$ per $\mathrm{g}$ pancreas). When arginine infusion was superimposed upon hyperglycemia (140-170min time period), the incremental plasma insulin response was slightly, although not significantly, reduced in both diabetic $(12.7 \mathrm{ng} / \mathrm{ml}$ per $\mathrm{g}$ pancreas) and phlorizin-treated diabetic (11.7) groups compared with controls (15.6).

The modulating effect of glucose on arginine-induced insulin secretion was calculated as the difference between the incremental insulin response to the second arginine stimulus minus that induced by the first arginine stimulus. The ability of hyperglycemia to augment arginine-stimulated insulin secretion was clearly impaired in diabetic compared with control rats $(3.01 \pm 1.06$ vs. $12.46 \pm 1.69 \mathrm{ng} / \mathrm{ml}$ per $\mathrm{g}$ pancreas, $P$ $<0.001$ ). Phlorizin treatment increased the modulating effect of hyperglycemia on arginine-induced insulin secretion to a value $(9.09 \pm 1.55 \mathrm{ng} / \mathrm{ml}$ per $\mathrm{g}$ pancreas) that was not significantly different from controls.

First and second phases of insulin secretion (Table $V$ ). The first phase of insulin secretion (calculated as the mean incremental plasma insulin concentration during the initial $10 \mathrm{~min}$, i.e., 80-90-min time period of the hyperglycemic clamp) was reduced by $99 \%$ in diabetic rats, while the second phase of insulin secretion (calculated as the mean incremental plasma insulin concentration during the $90-140$-min time period of the hyperglycemic clamp) was diminished similarly by $94 \%$
(Table V, top). Phlorizin treatment resulted in significant improvements in both the first and second phases of insulin secretion. The effect of phlorizin to augment the first and second phases of insulin secretion is more dramatically demonstrated when the incremental plasma insulin response is expressed per gram of pancreatic weight (Table V, bottom). As can be seen, both the first ( $4.36 \mathrm{vs} .3 .67 \mathrm{ng} / \mathrm{ml}$ per $\mathrm{g}$ pancreas) and second (4.89 vs. $4.50 \mathrm{ng} / \mathrm{ml}$ per $\mathrm{g}$ pancreas) phase insulin responses were completely normalized in the phlorizin-treated diabetic rats.

\section{Discussion}

At substrate concentrations within the physiologic range, glucose is the primary regulator of insulin secretion (16). It not only stimulates insulin release directly, but also modulates the action of other secretagogues on the beta cell (17). In normal man chronic hyperglycemia has been shown to augment in vivo insulin secretion $(18,19)$. In contrast, in rats with a reduced beta cell mass evidence has accumulated that chronic hyperglycemia may lead to a defect in beta cell function by decreasing glucose-stimulated insulin secretion and impairing the modulating effect of nonglucose secretagogues on insulin secretion $(6-9,20)$. Note, however, that all of the human studies involved healthy, nondiabetic subjects and the period of hyperglycemia was of short duration (days), whereas the animal studies involved prolonged periods of hyperglycemia (weeks) and were carried out in diabetic rats. Furthermore, all of these previous studies have two major shortcomings: First, islet cell function was examined in vitro and, to our knowl-

Table IV. Mean Plasma Insulin Response Expressed per Gram Pancreatic Weight or per Unit Pancreatic Insulin Content in Control and Diabetic Rats

\begin{tabular}{|c|c|c|c|c|c|c|}
\hline \multirow[b]{2}{*}{ Groups } & \multicolumn{3}{|c|}{$\begin{array}{l}\text { Mean plasma insulin concentration per pancreatic weight } \\
\text { ( } \mathrm{ng} / \mathrm{ml} / \mathrm{g} \text { pancreas) }\end{array}$} & \multicolumn{3}{|c|}{$\begin{array}{l}\text { Mean plasma insulin concentration per pancreatic insulin } \\
\text { content ( } \mathrm{ng} / \mathrm{ml} / \mathrm{ng} \text { pancreatic insulin) }\end{array}$} \\
\hline & Arginine & Hyperglycemia & $\begin{array}{l}\text { Arginine } \\
+ \text { hyperglycemia }\end{array}$ & Arginine & Hyperglycemia & $\begin{array}{l}\text { Arginine } \\
+ \text { hyperglycemia }\end{array}$ \\
\hline I Sham operated & $2.9 \pm 0.2$ & $4.4 \pm 0.5$ & $15.6 \pm 2.4$ & $73 \pm 7$ & $111 \pm 14$ & $399 \pm 63$ \\
\hline II Diabetic & $8.9 \pm 1.7^{*}$ & $1.5 \pm 0.3^{*}$ & $12.7 \pm 3.2$ & $204 \pm 40^{*}$ & $35 \pm 6^{*}$ & $289 \pm 73$ \\
\hline III Phlorizin-treated diabetic & $2.8 \pm 0.7$ & $4.8 \pm 0.5$ & $11.7 \pm 2.8$ & $73 \pm 20$ & $128 \pm 13$ & $311 \pm 75$ \\
\hline
\end{tabular}

$* P<0.01$ vs. sham-operated control and phlorizin-treated diabetic rats. 
Table V. First and Second Phase Plasma Insulin Responses during the Hyperglycemic Clamp Study Performed in Control and Diabetic Rats

\begin{tabular}{|c|c|c|}
\hline \multirow[b]{2}{*}{ Group } & \multicolumn{2}{|c|}{ Plasma insulin response $(\mathrm{ng} / \mathrm{ml} / \mathrm{min})$} \\
\hline & $\begin{array}{l}\text { First phase } \\
\text { (80-90 min) }\end{array}$ & $\begin{array}{l}\text { Second phase } \\
\text { (90-140 min) }\end{array}$ \\
\hline I Sham operated & $4.84 \pm 0.53$ & $5.94 \pm 0.86$ \\
\hline II Diabetics & $0.05 \pm 0.11^{* \neq}$ & $0.36 \pm 0.06^{* \pm}$ \\
\hline \multirow[t]{3}{*}{ III Phlorizin-treated diabetics } & $0.82 \pm 0.08^{*}$ & $0.92 \pm 0.11^{*}$ \\
\hline & \multicolumn{2}{|c|}{$\begin{array}{l}\text { Plasma insulin response } \\
(\mathrm{ng} / \mathrm{ml} / \mathrm{min} / \mathrm{g} \text { pancreas })\end{array}$} \\
\hline & $\begin{array}{l}\text { First phase } \\
\text { (80-90 min) }\end{array}$ & $\begin{array}{l}\text { Second phase } \\
(90-140 \mathrm{~min})\end{array}$ \\
\hline I Sham operated & $3.67 \pm 0.37$ & $4.50 \pm 0.65$ \\
\hline II Diabetics & $0.25 \pm 0.57^{*}$ & $1.86 \pm 0.31 *$ \\
\hline III Phlorizin-treated diabetics & $4.36 \pm 0.37$ & $4.89 \pm 0.58$ \\
\hline
\end{tabular}

* Different from group I, $P<0.001$.

${ }^{\ddagger}$ Different from group III, $P<0.001$.

edge, the impairment of beta cell function after chronic hyperglycemia has not been characterized in vivo. This is of considerable importance since the neuronal input to the pancreas and the influence of circulating hormones are lost when the islets are removed from the body. Moreover the preceding anesthesia, with an increase in circulating catecholamine levels, may alter beta cell function. Second, and more importantly, before the concept that chronic hyperglycemia is deleterious to beta cell function can be accepted, it must be shown that restoration of normoglycemia can return insulin secretion to normal. In the one rat study in which insulin treatment was used to normalize plasma glucose levels, no improvement in glucose-induced insulin secretion was observed (9). Interestingly, short-term insulin therapy in man has been shown to result in a partial improvement in insulin secretion in type II diabetic individuals $(21,22)$. However, it is not clear whether this improvement is related to the decline in plasma glucose concentration or to some other metabolic effect brought about by insulinization.

In the present study we have examined the effect of chronic hyperglycemia on insulin secretion in an awake, unstressed rat model. Partial $(90 \%)$ pancreatectomy was used to reduce beta cell mass and cause a chronic sustained, modest elevation in the plasma glucose concentration. With this procedure the residual $10 \%$ of the pancreas lying between the common bile duct and the duodenum is not touched, so that the remaining beta cells should be functionally intact. This avoids the concern of beta cell toxicity when streptozotocin is used to reduce beta cell mass. To evaluate beta cell function, we used the hyperglycemic clamp technique (14) since this allows the investigator to examine both the first and second phases of insulin secretion. The loss of first phase insulin secretion has been postulated to represent a specific and early defect in the pathogenesis of both type I $(23,24)$ and type II $(24-26)$ diabetes mellitus. Furthermore, its reversal with treatment of the hyperglycemia has never been reported in animal models of diabetes; in man, only occasional reports have demonstrated a partial correction after normalization of the plasma glucose concentration $(27,28)$.

$6 \mathrm{wk}$ after partial pancreatectomy the fasting plasma glucose concentration had risen to $\sim 120 \mathrm{mg} / \mathrm{dl}$, and moderately severe postmeal hyperglycemia $(250-300 \mathrm{mg} / \mathrm{dl})$ was present. These fed glucose values are similar to those reported by Orland et al. (29) and slightly greater than those reported by Bonner-Wier et al. (3). These small differences in the severity of diabetes is most likely accounted for by a number of factors including strain differences, variations in the age at which the surgical pancreatectomy was performed, and interanimal variation (30). Fasting plasma insulin levels were similar in diabetic and control rats but the post-meal plasma insulin response (Table I) was markedly impaired. When diabetic animals were treated with phlorizin, an inhibitor of renal glucose transport, both the fasting and post-meal plasma glucose concentrations were returned to normal without any change in either the basal or fed plasma insulin levels. Since phlorizin treatment did not affect pancreatic weight or pancreatic insulin content, any improvement in beta cell function can not be attributed to an increased beta cell mass or insulin content. Pancreatic weight and insulin content was similar in diabetic and phlorizin-treated diabetic rats and was $\sim 15 \%$ of that observed in the control animals. These data are in good agreement with those of Orland et al. (29), who showed that at 3 and 14 wk after pancreatectomy the remnant pancreatic weight and insulin content ranged from 12 to $15 \%$ of normal.

To examine the modulating effect of glucose on nonglucose secretagogues, we quantitated arginine-mediated insulin secretion at two plasma glucose concentrations (120 and 220 $\mathrm{mg} / \mathrm{dl}$ ) in control, diabetic, and phlorizin-treated diabetic rats. Since $90 \%$ of the pancreas was removed in both diabetic groups, it is obvious that the absolute amount of insulin secreted must be reduced. Therefore, the plasma insulin response was expressed, not only in absolute terms, but also per residual pancreatic weight and insulin content. During arginine infusion the basal plasma glucose concentration was similar in diabetics compared with control rats. The absence of an excessive glucose response to arginine often observed in other diabetic states can probably be related to the preserved ratio of beta/alpha cells in the pancreatectomized rat model (3). Similar steady state plasma arginine levels were achieved in control, diabetic, and phlorizin-treated diabetic rats. Diabetic animals, whose beta cells had been exposed to day-long hyperglycemia, demonstrated a marked hyperresponsiveness (threefold greater) to arginine when studied at their fasting plasma glucose concentration $(\sim 120 \mathrm{mg} / \mathrm{dl})$. These results are qualitatively quite similar to those of Leahy et al. (9), who used perfused pancreata from partially pancreatectomized and streptozotocin diabetic rats. Thus, both the in vitro studies, as well as our in vivo studies, demonstrate that chronic hyperglycemia has a potentiating effect on amino acid-mediated insulin secretion.

In marked contrast to the potentiating effect on argininemediated insulin release, chronic hyperglycemia severely impaired by $60-70 \%$ (Table IV) the pancreatic response to an acute glucose infusion. This reduction affected both the early (0-10 $\mathrm{min})$ and late (10-60 $\mathrm{min}$ ) plasma insulin responses, which were decreased by 93 and $60 \%$, respectively. This severe reduction in glucose-induced insulin secretion in vivo is consistent with a number of in vitro studies carried out with islet 
tissue obtained from diabetic rats (6-9). Most recently, it has been shown that a 48-h glucose infusion, designed to raise the plasma glucose concentration to $183 \pm 13 \mathrm{mg} / \mathrm{dl}$ in normal rats, leads to a defect in the beta cells' ability to respond to an acute hyperglycemic challenge in vitro (31). However, in the same study when glucose was infused for a similar period of time to raise the plasma glucose concentration to $164 \pm 4$ or $370 \pm 25$ $\mathrm{mg} / \mathrm{dl}$, no impairment in the insulin secretory response to acute hyperglycemia was observed. To ensure that the inability of our diabetic rats to respond during the hyperglycemic clamp was not due to beta cell exhaustion, animals were rechallenged with arginine while maintaining hyperglycemia at $220 \mathrm{mg} / \mathrm{dl}$. As can be seen in Table IV and Fig. 2 (bottom), the insulin response to this second arginine stimulus was slightly, although not significantly less than observed in controls, if expressed per pancreatic weight or insulin content. Thus, the deficient response to hyperglycemia can not be attributed to beta cell insulin depletion. Note that the incremental plasma insulin response to the second arginine stimulus in diabetic rats was of similar magnitude to the initial arginine challenge, indicating that the potentiating effect of glucose was already near maximal at a glucose concentration $(120 \mathrm{mg} / \mathrm{dl})$ similar to the fasting glucose level observed in the diabetic rats in vivo. This situation is quite different from that observed in the control animals where the second arginine stimulus (at a plasma glucose concentration of $220 \mathrm{mg} / \mathrm{dl}$ ) produced a fivefold greater insulin response (Table IV) than observed during the first arginine stimulus. Thus, the diabetic beta cell appears to be characterized by three specific alterations: $(a)$ a deficient insulin response, both first and second phases, to hyperglycemia; (b) a hypersensitivity to the potentiating effect of arginine under basal glycemic conditions; and $(c)$ an inability of hyperglycemia to augment the potentiating effect of arginine above that observed under basal glycemic conditions. Our interpretation of the arginine infusion studies is that the prolonged hyperglycemia observed in diabetic rats induces a state of chronic potentiation which is already maximal under the fasting hyperglycemic conditions observed in vivo.

To examine the role of hyperglycemia per se on the above three defects in insulin secretion, a separate group of diabetic animals was started on phlorizin treatment 2 wk postpancreatectomy, i.e., at the time when hyperglycemia is first noted to develop. Phlorizin, by inhibiting glucose reabsorption by the renal tubular cells, induced a state of persistent renal glucosuria and completely normalized both the fasting and postmeal plasma glucose levels without any alteration in the plasma insulin response. As can be seen in Table IV and Fig. 2 (top), normalization of the plasma glucose profile corrected all of the defects in insulin secretion observed in diabetic rats. Most noteworthy, the plasma insulin response to hyperglycemia by the residual beta cells from diabetic rats was completely normalized. This improvement in insulin secretion involved both the first and second phases of insulin release, which returned to values similar to those observed in control rats (Table V). One previous investigation has attempted to examine whether glycemic control in diabetic (streptozotocin induced) rats could reverse the defect in glucose-stimulated insulin secretion (22); in this study insulin therapy failed to improve beta cell function. However, there were several noteable differences between this study (22) and our own. First, the period of insulin therapy was quite short, only $24 \mathrm{~h}$, and this may have been of insufficient time to observe any improvement in insulin secretion. Second, the insulin treatment resulted in modest hypoglycemia, which of itself could impair insulin secretion. And lastly, exogenous insulin administration with resultant hyperinsulinemia has been shown to have a feedback inhibition of pancreatic insulin secretion (32). In the studies of Leahy et al. (31), where chronic (48 h) glucose infusion was associated with an acquired insulin secretory defect in response to an acute hyperglycemic stimulus, cessation of the glucose infusion for $72 \mathrm{~h}$ was associated with a return of insulin secretion to normal.

Long-term correction of hyperglycemia in diabetic rats also corrected the hyperresponsiveness to arginine. Thus, when the plasma arginine concentration was increased to $2 \mathrm{mM}$ and plasma glucose was maintained at basal levels, the mean plasma insulin response decreased from 8.9 to $2.8 \mathrm{ng} / \mathrm{ml}$ per $\mathrm{g}$ pancreas (Table IV), a value that was not significantly different from the control rats. Similarly, the potentiating effect of hyperglycemia $(220 \mathrm{mg} / \mathrm{dl})$ on arginine-mediated insulin secretion increased markedly to a value that was slightly, although not significantly, greater than in control animals.

Our observations may have particular relevance for understanding the pathogenesis of type II or non-insulin-dependent diabetes mellitus. The little data that are available in man suggest that pancreatic mass is reduced to approximately $60-70 \%$ of normal $(33,34)$ in non-insulin-dependent diabetes mellitus. Such a decrease, of itself, would not be sufficient to account for the marked insulinopenia observed in many type II diabetic patients, especially in those with fasting plasma glucose levels above $200-220 \mathrm{mg} / \mathrm{dl}$. It seems likely, therefore, that some factor(s) must be responsible for impairing insulin secretion in such individuals. On the basis of our results it is interesting to hypothesize that one such factor could be glucose itself. Thus, chronic hyperglycemia could be postulated to cause a "desensitization" of the beta cells' ability to respond to a glucose stimulus. Such a desensitization may be common to all cells in the body. Using the same partially pancreatectomized rat model, we recently have shown that chronic hyperglycemia leads to peripheral tissue insensitivity to the action of insulin (13). Other investigators have shown that hyperglycemia can down-regulate the glucose transport system in noninsulin dependent tissues, such as the cerebral cortex $(35,36)$. One could speculate that chronic sustained hyperglycemia causes a generalized down-regulation of glucose transport and metabolism in all cells of the body. This could account for such diverse observations as severe insulin resistance in peripheral $(13,37)$ and hepatic (38) tissues, impaired insulin secretion in response to glucose (but a normal response to nonglucose stimuli) $(6-9,39)$, and the development of symptoms of neuroglycopenia at "normal" plasma glucose levels in poorly controlled diabetic individuals (40). Our results also might help to explain the uniform improvement in insulin secretion observed after a number of diverse maneuvers, all of which have in common the ability to lower the plasma glucose concentration. Thus, acute (41) and chronic (42) caloric restriction, intensified insulin therapy (43), and sulfonylurea drugs $(44,45)$ all result in a significant lowering of the plasma glucose concentration and a concomitant increase in insulin secretion which may be sustained even after the therapy is 
discontinued. The therapeutic efficacy of these maneuvers may, in part, be related to their plasma glucose lowering effect, which secondarily leads to an improvement in insulin secretion.

In summary, our results demonstrate two important relationships between the plasma glucose concentration and insulin secretion: first, chronic (4 wk) sustained hyperglycemia markedly impairs the ability of the beta cell to respond to an acute glucose stimulus; second, chronic hyperglycemia induces a state of beta cell "potentiation" to nonglucose secretagogues such as arginine. These alterations in insulin secretion can be reversed completely with correction of the hyperglycemia.

\section{Acknowledgments}

The authors would like to thank Miss Jo Anne Palmieri for her expert secretarial assistance. Ms. Vicky Diaz provided technical assistance in performing the insulin determinations.

This work was supported in part by a grant from the Juvenile Diabetes Foundation (JDF185279 to G. I. Shulman). Dr. Rossetti is the recipient of JDF postdoctoral fellowship 386266. We are thankful to Drs. Susan Bonner-Wier and Gordon Wier for teaching us how to perform the partial pancreatectomy technique.

\section{References}

1. Gerich, J., M. Charles, and G. Grodsky. 1974. Characterization of the effects of arginine and glucose on glucagon and insulin release from the perfused rat pancreas. J. Clin. Invest. 54:833-842.

2. Pagliara, A., S. Stillings, B. Hover, D. Martin, and F. Matschinsky. 1974. Glucose modulation of amino acid-induced glucagon and insulin release in the isolated perfused rat pancreas. J. Clin. Invest. 54:819-832.

3. Bonner-Weir, S., D. F. Trent, and G. C. Weir. 1983. Partial pancreatectomy in the rat and subsequent defect in glucose-induced insulin release. J. Clin. Invest. 71:1544-1553.

4. Robertson, R. P., and D. Porte, Jr. 1973. The glucose receptor. A defective mechanism in diabetes mellitus distinct from beta adrenergic receptor. J. Clin. Invest. 52:870-876.

5. Cerasi, E., R. Luft, and S. Efendic. 1972. Decreased sensitivity of the pancreatic beta cells to glucose in prediabetic and diabetic subjects. Diabetes. 21:224-234.

6. Weir, G. C., E. T. Clore, C. J. Zmachinski, and S. Bonner-Weir. 1981. Islet secretion in a new experimental model for non-insulin-dependent diabets. Diabetes. 30:590-595.

7. Giroix, M. H., B. Portha, M. Kergoat, D. Bailbe, and L. Picon. 1983. Glucose insensitivity and amino-acid hypersensitivity of insulin release in rats with non-insulin-dependent diabetes. Diabetes. 32:445451.

8. Grill, V., and M. Rundfeldt. 1986. Abnormalities of insulin responses after ambient and previous exposure to glucose in streptozocin-diabetic and dexamethasone-treated rats. Diabetes. 35:44-51.

9. Leahy, J. L., S. Bonner-Weir, and G. C. Weir. 1984. Abnormal glucose regulation of insulin secretion in models of reduced $\beta$-cell mass. Diabetes. 33:667-673.

10. Deckert, T., V. Birk Lauridsen, S. Nistrup Madsen, and P. Mogensen. 1972. Insulin responses to glucose, tolbutamide, secretin, and isoprenaline in maturity-onset diabetes mellitus. Dan. Med. Bull. 19:222-226.

11. Ward, W. K., J. C. Beard, J. B. Halter, M. A. Pfeiffer, and D. Porte, Jr. 1984. Pathophysiology of insulin secretion in non-insulindependent diabetes mellitus. Diabetes Care 7:491-502.

12. Foglia, V. G. 1944. Caracteristicas de la diabetes en la rata. Rev. Soc. Argent. Biol. 20:21-37.
13. Rossetti, L., D. Smith, G. I. Shulman, D. Papachristou, and R. A. DeFronzo. 1987. Correction of hyperglycemia with phlorizin normalizes tissue sensitivity to insulin in diabetic rats. J. Clin. Invest. 79:1510-1515.

14. DeFronzo, R. A., J. Tobin, and R. Andres. 1979. Glucose clamp technique: a method for quantifying insulin secretion and resistance. Am. J. Physiol. 237:E214-E223.

15. Albano, J. D. M., R. P. Ekino, I. Maritz, and R. C. Turner. 1972. A sensitive, precise radioimmunoassay of serum insulin relying on charcoal separations of bound and free moieties. Acta Endocrinol. 70:487-509.

16. Hedeskov, C. J. 1980. Mechanism of glucose-induced insulin secretion. Physiol. Rev. 60:442-509.

17. Efendic, S., E. Cerasi, and R. Luft. 1971. Role of glucose in arginine-induced insulin release in man. Metab. Clin. Exp. 20:568579.

18. Ward, W. K., J. B. Halter, J. C. Beard, and D. Porte, Jr. 1984. Adaptation of $B$ and $A$ cell function during prolonged glucose infusion in human subjects. Am. J. Physiol. 246:E405-E411.

19. Del Prato, S., P. Sheehan, F. Leonetti, and D. Simonson. 1986. Effect of chronic physiologic hyperglycemia on insulin secretion and glucose metabolism. Diabetes. 35(Suppl. 1):748. (Abstr.)

20. Leahy, J. L., S. Bonner-Weir, and G. C. Weir. 1985. Abnormal insulin secretion in a streptozocin model of diabetes. Diabetes. 34:660-666.

21. Andrews, W. J., B. Vasquez, M. Nagulesparan, I. Klimes, J. Foley, R. Unger, and G. M. Reaven. 1984. Insulin therapy in obese, non-insulin-dependent diabetes induces improvements in insulin action and secretion that are maintain for two weeks after insulin withdrawal. Diabetes. 33:634-642.

22. Garvey, W. T., J. M. Olefsky, J. Griffin, R. F. Hamman, and O. G. Kolterman. 1985. The effect of insulin treatment on insulin secretion and insulin action in type II diabetes mellitus. Diabetes. 34:222-234.

23. Ganda, O. P., S. Srikanta, S. J. Brink, M. A. Morris, R. E. Gleason, S. Soeldner, and G. S. Eisenbarth. 1984. Differential sensitivity to $\beta$-cell secretagogues in "early" type I diabetes mellitus. Diabetes. 33:516-521.

24. Pfeiffer, M. S., J. B. Halter, and D. Porte, Jr. 1981. Insulin secretion of diabetes mellitus. Am. J. Med. 70:579-588.

25. Cerasi, E., R. Luft, and S. Efendic. 1972. Decreased sensitivity of the pancreatic beta cells to glucose in prediabetic and diabetic subjects: a glucose obese response study. Diabetes. 21:224-234.

26. Simpson, R. G., R. Benedetti, G. M. Grodsky, J. H. Karam, and P. H. Forsham. 1968. Early phase of insulin release. Diabetes. 17:684-692.

27. Turner, R. C., S. T. McCarthy, R. R. Holman, and E. Harris. 1976. Beta-cell function improved by supplementing basal insulin secretion in mild diabetes. Br. Med. J. 1:1252-1254.

28. Vague, P., and J.-P. Moulin. 1982. The defective glucose-sensitivity of the $\beta$-cell in non-insulin dependent diabetes. Improvement after twenty hours of normoglycemia. Metab. Clin. Exp. 31:139-142.

29. Orland, M. J., R. Chyn, and M. A. Permutt. 1985. Modulation of proinsulin messenger RNA after partial pancreatectomy in rats. $J$. Clin. Invest. 75:2047-2055.

30. Kaufmann, F., and R. R. Rodriguez. 1984. Subtotal pancreatectomy in five different rat strains: incidence and course of development of diabetes. Diabetologia. 27:38-43.

31. Leahy, J. L., H. E. Cooper, and G. C. Weir. 1986. Chronic hyperglycemia is associated with impaired glucose influence on insulin secretion. J. Clin. Invest. 77:908-915.

32. Liljenquist, J. E., D. L. Horwitz, A. S. Jennings, J. L. Chiasson, U. Keller, and A. H. Rubenstein. 1978. Inhibition of insulin secretion by exogenous insulin in normal man as demonstrated by C-peptide assay. Diabetes. 27:563-570.

33. Westermark, P., and E. Wilander. 1978. The influence of amy- 
loid deposits on the islet volume in maturity-onset diabetes mellitus. Diabetologia. 15:417-421.

34. Gepts, W., and P. M. Lecompte. 1981. The pancreatic islets in diabetes. Am. J. Med. 70:105-114.

35. Gjedde, A., and C. Crone. 1981. Blood-brain glucose transfer: repression in chronic hyperglycemia. Science (Wash. DC). 214:456457.

36. Matthei, S., R. Horuk, and J. M. Olefsky. 1986. Blood-brain glucose transfer in diabetes mellitus. Decreased number of glucose transporters at blood-brain barrier. Diabetes. 35:1081-1084.

37. DeFronzo, R. A., E. Ferrannini, and V. Koivisto. 1983. New concepts in the pathogenesis and treatment of non-insulin dependent diabetes mellitus. Am. J. Med. 74(Suppl. 1A):52-81.

38. Kolterman, O. G., R. S. Gray, J. Griffin, P. Burstein, J. Insel, J. A. Scarlett, and J. M. Olefsky. 1981. Receptor and postreceptor defects contribute to the insulin resistance in noninsulin-dependent diabetes mellitus. J. Clin. Invest. 68:957-969.

39. Pfeifer, M. A., J. B. Halter, and D. Porte, Jr. 1981. Insulin secretion in diabetes mellitus. Am. J. Med. 70:579-588.

40. DeFronzo, R. A., R. Hendler, and N. Christensen. 1980. Stimu- lation of counterregulatory hormonal responses in diabetic man by a fall in glucose concentration. Diabetes. 29:125-131.

41. Henry, R. R., P. Wallace, and J. O. Olefsky. 1986. Effects of weight loss on mechanisms of hyperglycemia in obese non-insulin dependent diabetes mellitus. Diabetes. 35:990-998.

42. Savage, P. J., L. J. Bennion, E. V. Flock, M. Nagulesparan, D. Mott, J. Roth, R. H. Unger, and P. H. Bennett. 1979. Diet-induced improvement of abnormalities in insulin and glucagon secretion and in insulin receptor binding in diabetes mellitus. J. Clin. Endocrinol. Metab. 48:999-1007.

43. Garvey, W. T., J. M. Olefsky, J. Griffin, R. F. Hamman, and O. G. Kolterman. 1985. The effect of insulin treatment on insulin secretion and insulin action in type II diabetes mellitus. Diabetes. 34:222-234.

44. Kolterman, O. G., R. S. Gray, G. Shapiro, J. A. Scarlett, J. Griffin, and J. M. Olefsky. 1984. The acute and chronic effects of sulfonylurea therapy in type II diabetes. Diabetes. 33:346-354.

45. Kosaka, K., T. Kuzuya, Y. Akanuma, and R. Hagura. 1980. Increase in insulin response after treatment of overt maturity-onset diabetes is independent of the mode of treatment. Diabetologia. 18:23-28. 